\title{
Smoking may prevent pouchitis in patients with restorative proctocolectomy for ulcerative colitis
}

\author{
M N Merrett, N Mortensen, M Kettlewell, D O Jewell
}

\begin{abstract}
Epidemiological studies have shown an increased risk of ulcerative colitis (UC) in non-smokers and particularly recent exsmokers. Patients with UC have an increased risk of pouchitis following ileal pouch-anal anastomosis, which may be a manifestation of the original disease susceptibility. The aim of this study was to test the hypothesis that smoking habit may influence the incidence of pouchitis. All patients with a functioning pouch $\geqslant 12$ months at one centre were assessed. Patients were excluded if (a) the original indication was not $U C(n=5)$, (b) the excised pouch showed histology diagnostic of Crohn's disease $(n=2)$, and (c) data were inadequate $(n=4)$. Smoking data were collected by questionnaire, or direct interview, or both. Ex-smokers were those who had stopped smoking $<7$ years before colectomy. Non-smokers included exsmokers who had stopped $>7$ years before colectomy. Pouchitis was defined as an increase in stool frequency $>8 /$ day with acute inflammation on biopsy specimen histology. Each presentation requiring treatment was regarded as an episode. For comparison smoking habit was assessed with regard to three other adverse outcomes - haemorrhage, sepsis, and pouch excision. Of 72 non-smokers (mean follow up 3.5 years) $18 \mathrm{had} 46$ episodes of pouchitis. Of 12 ex-smokers (mean follow up 3.3 years) four patients have had 14 episodes of pouchitis. Only one smoker from 17 has had a single episode of pouchitis. This shows that smokers have significantly less episodes of pouchitis compared with non-smokers $(p=0.0005)$ and ex-smokers $(p=0 \cdot 05)$. There was no association of smoking habit with other adverse outcomes.
\end{abstract}

(Gut 1996; 38: 362-364)

Gastroenterology Unit, The Radcliffe Infirmary, Oxford

M N Merrett

D P Jewell

Department of Surgery, John Radcliffe Infirmary Hospital, Oxford $\mathrm{N}$ Mortensen M Kettlewell

Correspondence to: Dr M N Merrett, Department of Gastroenterology, Monash Medical Centre, Clayton, Victoria 3168, Australia.

Accepted for publication 7 September 1995
Keywords: pouchitis, smoking, ileal pouch-anal anastomosis, ulcerative colitis.

Epidemiological studies show an increased risk of ulcerative colitis (UC) in non-smokers, particularly in recent ex-smokers. ${ }^{1-9}$ The interval between cessation of smoking and subsequent onset of colitis in ex-smokers is comparatively short and in two thirds of patients occurs within seven years. ${ }^{9}$ Conversely in Crohn's disease there is a positive association with smoking. 246910 The mechanism for the association between smoking habit and inflammatory bowel disease is unknown.
Ileal pouch-anal anastomosis (IPAA) has become the operation of choice in patients with UC following proctocolectomy. ${ }^{1-15}$ Despite this IPAA is associated with serious morbidity postoperatively and in the longer term. ${ }^{16}$ The most important longterm complication is pouchitis, which has a reported incidence of $7-45 \%$ depending on definition and whether histological confirmation is required. ${ }^{17-21}$ Although the pathogenesis of pouchitis is unknown, it is possible that chronic or recurrent pouchitis may represent recurrent inflammation similar to the UC disease process. ${ }^{17-22}$

The aim of this study was to test the hypothesis that smoking habit may influence the occurrence of pouchitis in patients with UC prior to proctocolectomy.

\section{Methods}

\section{Patients}

The records of 112 consecutive patients from one hospital who had had a functioning IPAA for at least 12 months were reviewed. Patients with excluded if (a) the original indication was not UC $(n=5)$, (b) the excised pouch showed histology diagnostic of Crohn's disease $(n=2)$, (c) data were inadequate. The remaining 101 patients were the subject of this analysis.

Smoking data were collated by questionnaire $(n=73)$ and direct interview $(n=93)$ over a two year period. Ex-smokers were patients who had given up less than seven years prior to proctocolectomy. Non-smokers included exsmokers who had given up more than seven years prior to proctocolectomy as well as lifelong non-smokers. Two patients had a sustained change in smoking habit after IPAA and the occurrence of pouchitis was related to the smoking habit at that time. All patients were followed up at designated clinics at one hospital and were followed up for two years (1990-1992) by one investigator (MM). For the purposes of this study pouchitis was defined as an increase in stool frequency to at least 8/day with biopsy specimen histology showing pronounced inflammation - that is, histopathology index $\geqslant 7 .{ }^{23}$ Patients usually had general malaise with occasional per anal bleeding and extraintestinal manifestations. Microbiological studies of stool were obtained routinely to exclude a specific pathogen as a cause for the diarrhoea. Each presentation requiring treatment was regarded as an episode. For comparison smoking habit was assessed against other adverse outcomes in this same patient group. These included haemorrhage, sepsis, and pouch excision. 
TABLE I Smoking habit, pouch type, and follow up

\begin{tabular}{|c|c|c|c|c|c|}
\hline & Number & $\begin{array}{l}\text { Age } \\
\text { (median) }\end{array}$ & $\begin{array}{l}\text { Sex } \\
M / F\end{array}$ & $\begin{array}{l}\text { Total } \\
\text { follow up }\end{array}$ & $\begin{array}{l}\text { Pouch } \\
\text { type }\end{array}$ \\
\hline $\begin{array}{l}\text { Non-smokers } \\
\text { Smokers } \\
\text { Ex-smokers }\end{array}$ & $\begin{array}{l}72 \\
17 \\
12\end{array}$ & $\begin{array}{l}33 \\
32 \\
41\end{array}$ & $\begin{array}{l}39 / 33 \\
12 / 5 \\
8 / 4\end{array}$ & $\begin{array}{l}255 \\
71 \\
40\end{array}$ & $\begin{array}{l}8 \mathrm{~S} / 31 \mathrm{~W} / 33 \mathrm{~J} \\
3 \mathrm{~S} / 8 \mathrm{~W} / 6 \mathrm{~J} \\
2 \mathrm{~S} / 5 \mathrm{~W} / 5 \mathrm{~J}\end{array}$ \\
\hline
\end{tabular}

Haemorrhage was defined as further surgical intervention requiring drainage of a haematoma. Sepsis was diagnosed in the presence of positive blood cultures or abscess formation, or both, confirmed either with imaging or at surgery.

\section{Statistical analysis}

The mean number of pouchitis episodes per group were compared with the mean score test. $^{24}$ The categorical data were formed into a contingency table and analysed with a log linear model, assuming that the distribution of frequencies was Poisson. The log likelihood ratio statistic was used to assess the 'fit' of the log linear model and to test any hypotheses. The log likelihood ratio statistic is $\chi^{2}$ distributed.

\section{Results}

The three groups had similar ages, male/female ratio, and pouch design, although an increase in age of ex-smokers was noted (Table I) $(p=N S)$. The mean score test was used to test the null hypothesis that the average number of pouchitis episodes was equal for non-smokers, smokers, and ex-smokers (Table II). The test of the hypothesis gave a $\chi^{2}$ of $15 \cdot 854$ on 2 degrees of freedom (df), which is significant at the 0.001 level. The mean number of pouchitis episodes was similarly assessed in paired analysis. The number of pouchitis episodes for nonsmokers is significantly more than for smokers $(p=0.0005)$, however the difference between non-smokers and ex-smokers was not significant. Ex-smokers had more pouchitis episodes than smokers $(p=0.05)$.

Contingency table analysis (Table II) was used to assess the hypothesis of no dependence between patients group and the occurrence of pouchitis. Of 72 non-smokers, 18 suffered episodes of pouchitis compared with only one

TABLE II Smoking habit and number of pouchitis episodes

\begin{tabular}{llllllllll}
\hline \multirow{2}{*}{ Group } & Number & 0 & 1 & 2 & 3 & 4 & 5 & 6 & Mean score \\
\hline Non-smokers & 72 & 54 & 5 & 6 & 2 & 3 & 1 & 1 & 0.639 \\
Smoker & 17 & 16 & 1 & 0 & 0 & 0 & 0 & 0 & 0.059 \\
Ex-smoker & 12 & 8 & 0 & 1 & 2 & 0 & 0 & 1 & $1 \cdot 167$ \\
\hline
\end{tabular}

TABLE III Other complications in patients with pouch function $\geqslant 1$ years (including early complications)

\begin{tabular}{lllll}
\hline & Number & Bleeding & Sepsis & $\begin{array}{l}\text { Pouch excision } \\
\text { (and indication) }\end{array}$ \\
\hline Non-smokers & 72 & 7 & 9 & 1 PF, 4S \\
Smokers & 17 & 2 & 3 & 0 \\
Ex-smokers & 12 & 0 & 1 & $1 \mathrm{P}$ \\
\hline
\end{tabular}

$\mathrm{PF}=$ poor function, $\mathrm{S}=$ sepsis, $\mathrm{P}=$ pouchitis. of 17 smokers $\left(\chi^{2}=3.717\right.$ on $\left.1 \mathrm{df} p=0.054\right)$. Of 12 ex-smokers four had episodes of pouchitis compared with smokers) $\left(x^{2}=3.779\right.$ on $1 \mathrm{df}$ $p=0.052$ ) at the 0.06 level (borderline significance). The hypothesis was accepted for nonsmokers and ex-smokers. There was no association between smoking habit and three other adverse outcomes - haemorrhage, sepsis, and pouch excision (Table III).

Two patients had a sustained change in smoking habit. Patient 1, a 52 year old woman stopped smoking one year before proctocolectomy in 1983. The patient recommenced smoking immediately after the IPAA procedure and continued for six years with excellent pouch function. In 1989 she again stopped smoking and suffered pouchitis within 12 months and has since had five further episodes with associated arthritis. Patient 2, a 24 year old man did not smoke before IPAA and for two years after the procedure. During those two years, there were three episodes of pouchitis with an asymmetrical polyarthritis. At this time he started smoking for the first time and has continued for six years to the time of assessment. He has not had any further pouchitis or acute flares of arthritis although some joint deformity persists.

\section{Discussion}

Pouchitis is a poorly understood late complication of IPAA. Much of the confusion particularly with regard to incidence relates to the variability of criteria used to diagnose pouchitis. The use of clinical criteria alone is unsatisfactory as patients with IPAA may develop diarrhoea for reasons other than inflammation in the ileal reservoir. Recently a pouch disease activity index has been proposed, which combines clinical, endoscopic, and histological appearance. ${ }^{25}$ Endoscopic appearances of 'inflammation' are highly subjective (in our experience) with significant interobserver error and so was not included. In this study we used both clinical criteria and biopsy specimen histology ${ }^{23}$ to diagnoses pouchitis.

The aetiopathogenesis of pouchitis is unknown and it seems plausible that pouchitis may be the end result of a number of essentially different disease processes. ${ }^{14}{ }^{17-22}$ Using clinical criteria Rauh et al identified two major subgroups of pouchitis. The first group experience one or two episodes only and respond well to antibiotics. The second group, however, suffer serious illness and have recurrent or chronic pouchitis, which is often resistant to antibiotics. This group often require sulphasalazine or corticosteroids to control symptoms. ${ }^{22}$ The last subgroup of pouchitis occurs exclusively in patients with prior UC and may resemble the original disease process with regard to clinical manifestations and histological level. Other mechanisms proposed for pouchitis include bacterial overgrowth and changed bile acid metabolism, 18-21 26-28 ischaemia, ${ }^{2930}$ and unrecognised Crohn's disease.

The protective role of smoking against UC is well reported. ${ }^{1-9}$ However, this is the first 
report of smoking habit in relation to the incidence of pouchitis. Our finding that smoking is protective against the subsequent onset of pouchitis needs to be confirmed with a larger series, but pouchitis needs to be accurately defined and include histological criteria.

The mechanism(s) by which smoking protects against intestinal inflammation (UC) are unknown. Smoking has been reported to affect mucosal immune function in both the respiratory tract ${ }^{31-33}$ and gastrointestinal tract $^{34}$ although in the last study only minor differences in IgA concentrations were identified. Smoking also affects mucus production ${ }^{35}$ and rectal blood flow, ${ }^{34}$ however the significance of these reports is unknown. Perhaps the most important finding is that smoking reduces mucosal permeability as measured by urinary recovery of ${ }^{51}$ chromium-EDTA. ${ }^{36}$

Regardless of the mechanism the finding that smoking (and probably nicotine) protects against pouchitis raised the possibility of therapeutic intervention. We have shown that barrier function ( ${ }^{51} \mathrm{chromium}-\mathrm{EDTA}$ permeation) is low in preclosure ileal pouch, which suggests that the ileal mucosa is at greatest risk in the first few weeks when exposed to a large antigen/toxin faecal load. ${ }^{19}$ The importance of these early events is underlined by the findings that the first episode of pouchitis usually occurs soon after ileostomy closure (mean $=3.5$ months). ${ }^{22}$ There is insufficient evidence at this stage to support the use of nicotine (and smoking) to prevent pouchitis. However, a controlled trial would be worthwhile.

This paper was an oral presentation at the Digestive Disease Week, Boston, USA, 1993.

The authors would like to thank Dr Bridget Hsu-Hage and Dr Phillip McCloud for help with the statistical analysis and D Shao Kai Lin for his help with preparation of the manuscript.

1 Harris $\mathrm{AD}$, Baird A, Rhodes J. Non smoking: a feature of ulcerative colitis. BMF 1982; 284: 706 .

2 Jick H, Walker AM. Cigarette smoking and ulcerative colitis. N Engl f Med 1983; 308: 261-3.

3 Logan RFA, Edmond M, Somerville KW, Langman MJS. Smoking and ulcerative colitis. $B M F$ 1984; 288: 1307

4 Tobin MV, Logan RFA, Langman MJS, McConnell RB Gilmore IT. Cigarette smoking and inflammatory bowel disease. Gastroenterology 1987; 93: 316-21.

5 Persson PG, Ahlbom A, Hellers G. Inflammatory bowel disease and tobacco smoke - a case-control study. Gut 1990; 31: 1377-81.

6 Lindberg E, Tysk C, Andersson K, Jarnerot G. Smoking and inflammatory bowel disease. A case control study. Gut 1988; 29: 352-7.

7 Motley RJ, Rhodes J, Ford GA, Wilkinson SP, Chesner IM, Asquith $\mathrm{P}$, et al. Time relationship between cessation of smoking and onset of ulcerative colitis. Digestion 1987; 37: smokin

8 Motley RJ, Rhodes J, Kay S, Morris TJ. Late presentation of ulcerative colitis in ex-smokers. Int $\mathcal{f}$ Colorect Dis 1988: 3: $171-5$.
9 Osborne MJ, Stansby GP. Cigarette smoking and its relationship to inflammatory bowel disease: a review. $\mathcal{f} R$ Soc Med 1992; 85: 214-6.

10 Somerville KW, Logan RFA, Edmond M, Langman MJS. Smoking and crohn's disease. BMF 1984; 289: 954-6.

11 Pemberton JH, Kelly KA, Beart RW, Dozois RR, Wolff BG, Ilstrup DM. Ileal pouch-anal anastomosis for chronic ulcerative colitis. Ann Surg 1987; 206: 504-13.

12 Mortensen N. Progress with the pouch-restorative procto colectomy for ulcerative colitis. Gut 1988; 29: 561-6.

13 Kohler LW, Pemberton JH, Zinsmeister AR, Kelly KA Quality of life after proctocolectomy: a comparison of brooke ileostomy, koch pouch and ileal pouch-anal anastomosis. Gastroenterology 1991; 101: 679-84

14 Philipps RKS. Pelvic pouches. Br f Surg 1991; 78: 1025-6. 15 Pena JP, Gremlo BT, Rotherberger DA. Ileal pouch-ana anastomosis: state of the art. Baillieres Clin Gastroenterol 1992; 6: 113-28

16 Galandivk S, Scott NA, Dozois RR, Kelly KA, Ilstrup DM, Beart RW, et al. Ileal pouch-anal anastomosis: reoperation for pouch-related complications. Ann Surg 1990; 10: f46-54.

17 Knobler H, Ligumsky M, Okon E, Ayalon A, Nesler R Rachmilewitz D, Pouch ileitis - recurrence of inflammatory bowel disease in the ileal reservoir. Am $\mathcal{F}$ Gastroentero 1986; 81: 199-201.

18 Dozois RR, Goldberg SM, Rothenberger DA, Utsunomiya J, Nicholls RJ, Cohen Z, et al. Restorative proctocolectomy with ileal reservoir. Int $\mathcal{f}$ Colorect Dis 1986; 1: 2-19.

19 Merrett MN, Soper N, Mortensen N, Jewell DP. Intestinal permeability in the ileal pouch. Gut (in press).

20 Madden MV, Farthing MJG, Nichols RJ. Inflammation in ileal reservoirs: 'pouchitis'. Gut 1990; 31: 247-9.

21 de Silva HJ, Kettlewell MGW, Mortensen NJ, Jewell DP. Acute inflammation in ileal pouches (pouchitis). Eur $\mathcal{f}$ Acute inflammation in ileal pouches (pour

22 Rauh SM, Schoetz DJ, Roberts PL, Murray J, Coller JA, Veidenheimer MC. Pouchitis - Is it a wastebasket diagnosis? Dis Colon Rectum 1991; 34: 685-9.

23 Moskowitz RL, Shepherd NA, Nicholls RJ. An assessment of inflammation in the reservoir after restorative proctocolectomy with ileal reservoir. Int $\mathcal{F}$ Colorect Dis 1986; 1 : 167-74.

24 Bhapkar VP. On the analysis of contingency tables with a quantitative response. Biometrics 1968; 24: 329-38.

25 Sandborn WJ, Tremaine WJ, Batts KP, Pemberton JH, Philipps SF. Definition of pouchitis following ileal pouchanal anastomosis: a pouchitis disease activity index. Gastroenterology 1993; 104: A775.

26 O'Connell PR, Rankin DH, Weiland LH, Kelly KA Enteric bacteriology, absorption, morphology and empty-
ing after ileal pouch-anal anastomosis. Br f Surg 1986; 73: ing after

27 Luukonen P, Valtonen V, Sironen A, Sipponen P, Jarviren $\mathrm{H}$. Faecal bacteriology and reservoir ileitis in patients operated on for ulcerative colitis. Dis Colon Rectum 1988; 31: 864-7.

28 Nasmyth DG, Godwin PGR, Dixon MF, Williams NS, Johnston D. Ileal ecology after pouch-anal anastomosis or ileostomy: a study of mucosal morphology, faecal bacteriology, faceal volatile fatty acids, and their interrelationship. Gastroenterology 1989; 96: 817-24.

29 Hosie K, Sachaguchi M, Tudor R, Gourevitch P, Jarviren $H$. Caecal bacteriology and reservoir ileitis in patients operated on for ulcerative colitis. Dis Colon Rectum 1988; 31: $864-7$.

30 Levin KE, Pemberton JH, Philipps SF, Zinsmeister AR, Pezim ME. Role of oxygen free radicals in the aetiology of pouchitis. Dis Colon Rectum 1992; 35: 452-6.

31 Holt PG. Immune and inflammatory function in cigarette smokers. Thorax 1987; 42: 241-9.

32 Miller LG, Goldstein G, Murphy M, Ginns LC. Reversible alterations in immunoregulatory $\mathrm{T}$ cells in smoking. Chest 1982; 5: 527-9.

33 Cope GF, Heatley RV, Kelleher J. Smoking and colonic mucus in ulcerative colitis. $B M 7$ 1986; 293: 481 .

34 Rasp FL, Chawson CDC, Hoida LR, Repine JE. Reversible impairment of the adherence of alveolar macrophages from
cigarette smokers. Am Rev Resp Dis 1978; 118: 979-86.

35 Srivastava ED, Barton JR, O'Mahony S, Philipps DIM, Williams GF, Matthews N, et al. Smoking, humoral immunity and ulcerative colitis. Gut 1991; 32: 1016-9.

36 Prytz H, Benoni C, Tagesson C. Does smoking tighten the gut. Scand F Gastroenterol 1989; 24: 1084-8. 